\title{
Advanced Machine Learning and Big Data Analytics in Remote Sensing for Natural Hazards Management
}

\author{
Francisco Martínez-Álvarez ${ }^{1, *}$ and Dieu Tien Bui ${ }^{2}$ (1) \\ 1 Data Science and Big Data Lab, Pablo de Olavide University, ES-41013 Seville, Spain \\ 2 Geographic Information System Group, Department of Business and IT, University of South-Eastern \\ Norway, N-3800 Bø i Telemark, Norway; dieu.t.bui@usn.no \\ * Correspondence: fmaralv@upo.es; Tel.: +34-954-977-370
}

Received: 9 January 2020; Accepted: 9 January 2020; Published: 16 January 2020

\begin{abstract}
This editorial summarizes the performance of the special issue entitled Advanced Machine Learning and Big Data Analytics in Remote Sensing for Natural Hazards Management, which was published at MDPI's Remote Sensing journal. The special issue took place in years 2018 and 2019 and accepted a total of nine papers from authors of thirteen different countries. So far, these papers have dealt with 116 cites. Earthquakes, landslides, floods, wildfire and soil salinity were the topics analyzed. New methods were introduced, with applications of the utmost relevance.
\end{abstract}

Keywords: data mining; big data; remote sensing; GIS; spatio-temporal analysis; information fusion; natural hazards

Natural hazards are extreme and unexpected threats resulting from natural processes of the Earth, such as landslides, floods, hurricanes, tornadoes, volcanoes or any other natural phenomena that may cause harm to humans.

In that context, this Special Issue encouraged authors to share recent advances in natural hazards management with a particular emphasis on issues addressed by means of advanced machine learning, big data analytics and remote sensing techniques.

A huge amount of data are stored in almost all disciplines. Remote sensing is not an exception, since very large time series or high resolution satellite and aerial images are sources of valuable information. How to extract useful information from these big data sources is not, by contrast, an easy task, due to the computational and infrastructural cost it involves.

Very powerful approaches have been developed in the context of advanced machine learning and big data analytics during the last few years. Such approaches deal with large datasets, considering all samples and measurements, and include many additional features. Among them, advanced machine learning and big data methods are used for extracting relevant patterns, and high performance computing and data visualization are being successfully applied to the field of remote sensing nowadays.

For all the aforementioned methods, the scientific community was invited to contribute to this special issue by submitting novel and original research addressing at least one of the following topics, in the context of data science and big data:

1. Recent advances in information fusion for natural hazards management.

2. Recent advances in spatial modeling for natural hazards management.

3. Recent advances in temporal modeling for natural hazards management.

4. Real-world case studies with findings of clear interest to the scientific community.

Authors were also encouraged to share code and data so that their studies could be easily reproduced and could serve as seeds for future improvements. 
From all the submissions received, only those with very high quality scientific content and clear contributions at the cutting edge were accepted, after rigorous peer review. A total of nine papers were accepted by 45 different authors, with the following geographical distribution:

1. China: 11;

2. Vietnam: 7;

3. Iran: 6;

4. Malaysia: 6;

5. Germany: 3;

6. Serbia: 3;

7. Spain: 2;

8. Korea: 2;

9. Australia: 1;

10. Belgium: 1;

11. India: 1;

12. Taiwan: 1;

13. Norway: 1.

The submissions received mainly addressed earthquakes, landslides, floods, wildfires and soil salinity.

Thus, the authors in [1] conducted a spatio-temporal seismicity analysis for hazard assessment by means of unsupervised techniques. In particular, the well-known k-means clustering algorithm used by including the time parameter. Data from the Yongshaba mine in China were used to evaluate the performance. Alizadeh et al. [2] studied urban earthquake vulnerability by introducing a novel hybrid method. Hence, a new index was constructed in the context of a hybrid framework fusing analytical network processes and artificial neural networks. This index was then applied to Tabriz, Iran. One of the most interesting outcomes, as claimed by the authors, is that it can be easily replicated and applied to other urban regions around the world for sustainability and environmental management. The identification of collapsed buildings using post-earthquake satellite imagery and convolutional neural networks was analyzed in [3]. As a case study, the 2010 Haiti earthquake was used to evaluate the goodness of the proposed approach. One of the most significant difficulties that the authors had to deal with was the imbalance in data. Convolutional neural networks were applied to two different test regions with remarkable results.

Three works have been published related to landslides. In [4] was proposed a method for landslide detection and susceptibility mapping by AIRSAR data using support vector machine and index of entropy models in Cameron Highlands, Malaysia. To compare both methods' performances, ten features were retrieved from satellite images, including almost 100 events. Very promising results were reported in terms of accuracy. A novel integrated approach of relevance vector machine optimized by imperialist competitive algorithm for spatial modeling of shallow landslides can be found in [5] (and its subsequent erratum [6]). For this purpose, a spatial database from Lang Son city, Vietnam, including 14 features and an inventory map was first created. Given the results achieved, it can be concluded that the method is quite promising to help decision makers for managing landslide prone areas. A work for evaluating earthquake and rainfall-induced landslide susceptibility using the LiDAR DEM can be found in [7]. In particular, the authors developed GIS-based multiple statistical models and data mining techniques for this particular purpose. The main novelty lies in the joint evaluation of landslides triggered by earthquakes, and, later, followed by heavy rainfall events. The Chuetsu region in Japan was considered to assess the performance of the proposal, concluding that it can be applied to different areas.

Floods are one the most hazardous disasters in the world due to the dramatic losses that they can cause. Wang et al. [8] developed a hybrid GIS multi-criteria decision-making method for flood susceptibility mapping, using Shangyou, China, as a study case. The authors considered up to eleven well-established features along with historical data. They concluded that the method could be used in regions with similar environments in order to manage floods and prevent casualties. 
Wildfires occur quite often worldwide and can devastate large areas of forest and cause personal losses. The performances of both bivariate and multivariate models to predict wildfires across a fire-prone landscape are evaluated in [9]. A total of 132 events from the Zagros region, Iran, with twelve features, formed the database. Additionally, two wildfire probability maps were generated. The authors concluded that the use of ensemble learning is the most efficient for this problem.

One of the most damaging natural hazards for agriculture is the increasing soil salinity associated with climate change. Thus, a soil salinity mapping using satellite imagery and machine learning was published in [10]. As a case study, the authors used the Mekong river delta at Ben Tre, Vietnam. The authors compared the performances of five well-known machine learning algorithms in a dataset composed of 63 samples retrieved from SAR Sentinel-1.

Although there is much work to be done, the editors of this special issue truly hope that these papers will help and inspire other authors to develop new methods and analyze new areas, in order to prevent and better manage natural hazards.

Acknowledgments: The guest editors would like to express their sincerest gratitude to Remote Sensing's in-house editors and reviewers for their wonderful work and effort. Without their support the efficient handling of all the manuscripts that were received (article average processing time was 43.7 days), it would not have been possible to publish this special issue.

Conflicts of Interest: The authors declare no conflict of interest.

\section{References}

1. Shang, X.; Li, X.; Morales-Esteban, A.; Asencio-Cortés, G.; Wang, Z. Data Field-Based K-Means Clustering for Spatio-Temporal Seismicity Analysis and Hazard Assessment. Remote Sens. 2018, 10, 461. [CrossRef]

2. Alizadeh, M.; Ngah, I.; Hashim, M.; Pradhan, B.; Pour, A.B. A Hybrid Analytic Network Process and Artificial Neural Network (ANP-ANN) Model for Urban Earthquake Vulnerability Assessment. Remote Sens. 2018, 10, 975. [CrossRef]

3. Ji, M.; Liu, L.; Buchroithner, M. Identifying Collapsed Buildings Using Post-Earthquake Satellite Imagery and Convolutional Neural Networks: A Case Study of the 2010 Haiti Earthquake. Remote Sens. 2018, 10, 1689. [CrossRef]

4. Tien Bui, D.; Shahabi, H.; Shirzadi, A.; Chapi, K.; Alizadeh, M.; Chen, W.; Mohammadi, A.; Ahmad, B.B.; Panahi, M.; Hong, H.; et al. Landslide Detection and Susceptibility Mapping by AIRSAR Data Using Support Vector Machine and Index of Entropy Models in Cameron Highlands, Malaysia. Remote Sens. 2018, 10, 1527. [CrossRef]

5. Tien Bui, D.; Shahabi, H.; Shirzadi, A.; Chapi, K.; Hoang, N.D.; Pham, B.T.; Bui, Q.T.; Tran, C.T.; Panahi, M.; Bin Ahmad, B.; et al. A Novel Integrated Approach of Relevance Vector Machine Optimized by Imperialist Competitive Algorithm for Spatial Modeling of Shallow Landslides. Remote Sens. 2018, 10, 1538. [CrossRef]

6. Tien Bui, D.; Shahabi, H.; Shirzadi, A.; Kamran Chapi, K.; Hoang, N.D.; Pham, B.T.; Bui, Q.T.; Tran, C.T.; Panahi, M.; Bin Ahmad, B.; et al. A Novel Integrated Approach of Relevance Vector Machine Optimized by Imperialist Competitive Algorithm for Spatial Modeling of Shallow Landslides. Remote Sens. 2018, 11, 1583. [CrossRef]

7. Dou, J.; Yunus, A.P.; Tien Bui, D.; Sahana, M.; Chen, C.W.; Zhu, Z.; Wang, W.; Thai Pham, B. Evaluating GIS-Based Multiple Statistical Models and Data Mining for Earthquake and Rainfall-Induced Landslide Susceptibility Using the LiDAR DEM. Remote Sens. 2019, 11, 638. [CrossRef]

8. Wang, Y.; Hong, H.; Chen, W.; Li, S.; Pamučar, D.; Gigović, L.; Drobnjak, S.; Tien Bui, D.; Duan, H. A Hybrid GIS Multi-Criteria Decision-Making Method for Flood Susceptibility Mapping at Shangyou, China. Remote Sens. 2018, 11, 62. [CrossRef]

9. Jaafari, A.; Mafi-Gholami, D.; Thai Pham, B.; Tien Bui, D. Wildfire Probability Mapping: Bivariate vs. Multivariate Statistics. Remote Sens. 2019, 11, 618. [CrossRef]

10. Hoa, P.V.; Giang, N.V.; Binh, N.A.; Hai, L.V.H.; Pham, T.D.; Hasanlou, M.; Tien Bui, D. Soil Salinity Mapping Using SAR Sentinel-1 Data and Advanced Machine Learning Algorithms: A Case Study at Ben Tre Province of the Mekong River Delta (Vietnam). Remote Sens. 2019, 11, 128. [CrossRef] 